\title{
XENOFOBIA Y RACISMO EN CONTRA DE LOS EMIGRANTES REPRESENTADOS EN LA CUENTÍSTICA ECUATORIANA
}

\section{XENOPHOBIA AND RACISM AGAINST MIGRANTS REPRESENTED IN THE ECUADORIAN STORIES}

\author{
Yovany Salazar Estrada, PhD.
}

Doctor en Filosofía en un Mundo Global y en Literatura Hispanoamericana (España). Docente de la Carrera de Lengua Castellana y Literatura de la Universidad Nacional de Loja, Ecuador. ysalazararec2002@yahoo.es

\section{ARTÍCULO DE REFLEXIÓN}

Recibido: 2 de junio de 2017

Aceptado: 31 de octubre de 2017

\section{RESUMEN}

El artículo se propone analizar las expresiones de xenofobia y racismo en contra de los ecuatorianos que han emigrado con rumbo hacia Estados Unidos y España, conforme se representa en los cuentos publicados durante las últimas cuatro décadas. En el desarrollo del estudio se fundamenta, ejemplifica y analiza la recreación literaria de dos aspectos problemáticos que golpean a los protagonistas de la emigración: el tratamiento discriminatorio que reciben al ser tratados como los "otros" en los países de destino; y, algunas manifestaciones de xenofobia y racismo, en contra de los ecuatorianos mientras permanecen en el extranjero.

Palabras clave: Cuento ecuatoriano y emigración, emigración internacional, el "Otro", racismo, xenofobia.

\section{ABSTRACT}

The article aims to analyze the expressions of xenophobia and racism against Ecuadorians who havemig rated heading to the United States and Spain, as depicted in 
the stories published overt he past four decades. In the developing of the study, it bases, illustrates and analyzes the literary creation of two problematicas pectsthat hit the protagonists of emigration: the discriminatory treatment they receiveby being treated as "others" in the countries of destination; and, somem anifestations of xenophobia and racism against Ecuadorian while stay in gabroad.

Keywords: Ecuadorian story and migration, international migration, the "Other", racism, xenophobia.

\section{INTRODUCCIÓN}

El territorio que en la actualidad ocupa la República del Ecuador ha estado marcado por la migración permanente de sus habitantes; sin embargo, entre 1999 y 2004, como consecuencia de la severa crisis económica, social y política que afectó al Ecuador y la conjunción de otros factores causales de orden natural, cultural, antropológico, psicológico y hasta personal de los protagonistas del desplazamiento físico se produjo una verdadera "estampida emigratoria" (Ramírez, 2005) de ecuatorianos.

Como es lógico que acontezca, las problemáticas vinculadas con este complejo fenómeno sociológico se han constituido en objeto de representación, entendida como la "imitación o copia de la realidad, teniendo como requisito fundamental, la verosimilitud" (Estébanez, 1999, p. 924) y han sido recreados en las más variadas expresiones de la dimensión artística de la cultura: música, pintura, teatro, cine y literatura, en sus diversos géneros: poesía, novela, cuento ${ }^{1}$, ensayo, crónica y testimonio.

En el género cuentístico, en lo atinente a la representación de la migración, interna e internacional, se pueden diferenciar dos grupos de obras de narrativa breve. En primer término se integran los cuentos que aluden a la migración interna, con siete textos

\footnotetext{
${ }^{1}$ Se entiende por cuento a "una clase de mensaje narrativo breve, elaborado con la intención muy específica (...) de generar un efecto o impresión momentánea e impactante en el destinatario (...) y cuya composición lingüística pareciera restringida por la escogencia focalizadora de un tema (...) narrado a partir de una serie de macro proposiciones únicas (...) no vinculadas semánticamente con ningún otro texto narrativo adherente o coexistente, lo que a su vez lo reviste de una relativa autonomía semántica y formal (Barrera, 1997, p.34).
} 
narrativos que recrean la emigración interprovincial e interregional proveniente desde la ciudad y provincia de Loja; seis cuentos sobre la emigración desde el sector rural y pequeños poblados de la provincia del Guayas, la región Costa, en general, e incluso de otras provincias de la Sierra, en dirección a la ciudad de Guayaquil y seis cuentos que aluden a la emigración desde los sectores campesinos y pueblos de escaso y mediano número de habitantes de la Sierra andina del Ecuador, con rumbo hacia las ciudades de Quito y Cuenca.

El segundo grupo de cuentos, que son los que interesan en el desarrollo de este trabajo, tienen como trama argumental y referente real la salida de ecuatorianos en dirección hacia algunos países del Hemisferio Norte, en especial Estados Unidos y España (Salazar, 2016, p. 21). De esta clase de obras de narrativa breve se ha llegado a determinar la existencia de tres cuentarios ${ }^{2}$, diecisiete cuentos que se refieren a la emigración desde el Ecuador con rumbo hacia Estados Unidos; dieciocho en torno a la emigración de ecuatorianos a España; y, cuatro cuentos que recrean la salida desde el Ecuador con destino hacia otros países de Europa y del resto del mundo.

No obstante la existencia de este significativo corpus narrativo que tiene como referente real la salida de ecuatorianos, a diferencia de los múltiples estudios sobre cuentos de temáticas similares en otros países del universo hispánico (Salazar, 2016, p. 22), en el Ecuador todavía son muy escasos los trabajos analíticos o valorativos sobre el llamado "cuento emigratorio", motivo por el cual solo se podría citar el trabajo de Raúl Serrano Sánchez, quien desde la perspectiva del sujeto migrante, contextualiza (en lo social y literario), presenta, describe y analiza, con énfasis en la dimensión temática y metafórica, una veintena de cuentos sobre la emigración internacional de ecuatorianos, en dirección hacia Estados Unidos y España (Cfr. Serrano, 2013, pp.193-222).

Con fundamento en esta insuficiencia investigativa, el presente trabajo se propone analizar la representación del "otro", la xenofobia y el racismo del que son víctimas los personajes ficticios que recrean a los emigrantes ecuatorianos en tres cuentarios y nueve cuentos publicados entre 1981 y 2014 , en los que son muy evidentes las

${ }^{2}$ El término cuentario constituye un neologismo utilizado para referirse a un conjunto de cuentos o un libro de cuentos. En Ecuador ha sido empleado por unos pocos cuentistas como Raúl Pérez Torres, Raúl Vallejo Corral, Raúl Serrano Sánchez y Galo Guerrero Jiménez. 
alusiones a estas problemáticas relacionadas con la emigración internacional de ecuatorianos.

Para el desarrollo del trabajo analítico previsto se empleó la metodología y las técnicas propias de la investigación bibliográfico documental y en esta perspectiva se recurrió a dos tipos de fuentes de información: las primarias, que comprenden los textos de los cuentos seleccionados como objeto de estudio; y las secundarias, que incluye otro tipo de información contenida en distintos soportes, a través de los cuales se permitió acercarse a la fundamentación teórico-conceptual y referentes empíricos en torno a la construcción del "otro", la xenofobia y el racismo, en contra de los ecuatorianos que residen fuera del país de origen.

En la perspectiva de alcanzar el objetivo previsto se partió de una lectura inicial de todos los cuentos ecuatorianos que representan y recrean, literariamente, el fenómeno sociológico de la emigración internacional y de las obras que abordan la construcción del "otro", la xenofobia y el racismo; para, en una segunda fase, realizar una nueva lectura de los cuentos estudiados, con la finalidad de extraer las citas textuales, que se las consideró más representativas y pertinentes, para el desarrollo del análisis crítico, valorativo e interpretativo previsto.

\section{REVISIÓN TEÓRICA}

\section{Los emigrantes ecuatorianos como los "otros" en los países de destino}

Una de las más complejas y desagradables dificultades que experimentan los emigrantes ecuatorianos, cuando arriban a los países de destino y mientras permanecen en ellos, es la de ser tratados como los "otros", los extranjeros, los forasteros, los desechables, los descartables, los sustituibles; por lo mismo se convierten en fáciles víctimas de la exclusión, la discriminación, la explotación, la dominación y el menosprecio por ser portadores de rasgos culturales distintos, que despiertan la desconfianza de algunos nativos (Salazar, 2014, pp. 181-186).

Obviamente que el proceso de construcción del "otro", de similar manera a lo que acontece con la xenofobia y el racismo, siempre se lo hace desde el punto de vista e intereses de quienes detentan el poder en los Estados nacionales del Hemisferio Norte. 
Como expresa lain Chambers, se lo ha hecho desde "la mirada de Dios hoy secularizada, que ha descendido a la tierra para hablar en la mesurada voz del experto, del científico, del intelectual" (1995, p.176).

En relación a la construcción del "otro", en la época contemporánea y con la masiva llegada de emigrantes ecuatorianos hacia España, por ejemplo, es fácil advertir la violación de los derechos de que son víctimas nuestros compatriotas en la nación ibérica, por el hecho de ser los "otros"; pues como dice un investigador de esta problemática:

les tratamos como si fueran ciudadanos de segunda clase y eso en una sociedad que se precia de haber avanzado mucho en la materia... nos da, por ejemplo, miedo que voten, pero si pagan impuestos... si tienen obligaciones, cómo no concederles derechos iguales. Si no tienen una auténtica igualdad de derechos, no se integrarán a nuestra sociedad; tal cosa es una condición previa para que la integración tenga lugar (Murillo, 2009, p. 104).

Otras formas de evidenciar la violación de los derechos humanos, en contra de los emigrantes provenientes del Ecuador, en tanto se los cataloga como los "otros", en palabras de Javier Murillo, están en los abusos que cometen los propietarios o intermediarios de pisos; así como en el trato que les dan los funcionarios administrativos, la policía, las largas colas para renovar papeles, el no reconocerles unos derechos mínimos como trabajadores (p. 117).

En España, en expresiones de Albert Mora Castro, se reproduce la paradoja del capitalismo contemporáneo, sistema en el cual las mercancías circulan con total libertad, pero las personas tienen una serie de restricciones, puesto que "cada vez hay más fronteras, no solamente las fronteras físicas, sino también las fronteras simbólicas, una frontera firme entre el 'nosotros' y el 'de fuera', que es una frontera que no simplemente es una frontera social, es también una frontera jurídica, porque el que es de 'nosotros' tiene unos derechos y el 'de fuera' tiene otros" (2011, p.2).

Un claro ejemplo de lo expresado constituye las alambradas, las mallas y los nuevos "muros de la infamia" y la vergüenza que se han erigido para "separar a los seres humanos, donde hoy mismo son heridos y abaleados todos los días los réprobos que 
intentan cruzarlos, para acceder al mundo de los elegidos". Tampoco hay que olvidar que algunos de estos muros han sido pensados y erigidos para impedir el arribo de migrantes provenientes del Hemisferio Sur. De todos los existentes, "el mayor y más bárbaro de ellos es el construido por Estados Unidos en su frontera con México, para impedir que mexicanos (antiguos dueños de ese territorio) puedan ingresar sin permiso a su territorio. Tiene casi 5 metros de alto y 563 kilómetros de longitud, está hecho de acero y concreto y tiene tres barreras de contención, alta iluminación y sensores electrónicos" (Núñez, 2014).

En relación directa con la construcción de este muro, en uno de los relatos testimoniales de Galo Galarza Dávila se pone de manifiesto la hipocresía imperial de Estados Unidos, puesto que, aunque el gobierno norteamericano haya difundido y celebrado a lo grande la caída del muro de Berlín, en 1989, en la práctica constituyen puras lágrimas de cocodrilo "porque, a esa misma hora, cuando los alemanes derribaban su muro, estos gringos estaban edificando otro muro más grande, más sólido y más terrible en su frontera con México, o en su frontera con América Latina mejor" (2009, pp. 71-72).

Al leer los textos de los otros cuentos ecuatorianos seleccionados como corpus narrativo de análisis se patentiza que el proceso sociohistórico y geopolítico de construcción del sujeto emigrante ecuatoriano como el "otro" en los Estados nacionales de destino está muy bien representado en estas obras de narrativa breve. Así, sobre la mirada peyorativa que reciben los latinos en Estados Unidos constituye un claro ejemplo "Listen, mon", de Zoila María Castro, en el cual se advierten las permanentes dificultades, derivadas de los prejuicios estigmatizadores que se han forjado algunos estadounidenses en contra de los inmigrantes provenientes del Sur del continente y entre ellos los ecuatorianos, ya que "los 'latinos' tenían bien cimentada reputación de pendencieros, alcohólicos y mariguaneros" (1981, p. 142).

En relación a la percepción estereotipada que tienen algunos nacionales de Estados Unidos respecto de las mujeres migrantes de origen latinoamericano, esta prejuiciosa actitud se patentiza, con toda claridad, en el cuento "47 Coldwater Drive o la pregunta", de Gilda Holst Molestina. En este relato, el médico norteamericano pone en evidencia las razones de su preferencia por las mujeres de origen latino, motivo por el cual tiene esposa y amante ecuatorianas, porque como dijo en una ocasión: "Las americanas lo inhiben un poco, en cambio, se siente muy cómodo con las latinas. Y a Julia le encanta 
ser la latina del grupo, hablar por los codos, soltar de vez en cuando algunas malas palabras en inglés y en español, tocar a los amigos y amigas más de lo que se acostumbra" (2006, p. 60).

En el cuento "La niña Pupusa", de Eliécer Cárdenas Espinoza, se advierte que determinados grupos sociales de clase media alta, que habitan en algunos antiguos barrios residenciales de la ciudad de Nueva York, huyen de la presencia cercana de los migrantes laborales provenientes de Sur del continente, como es el caso de una familia judía que vende la vetusta casa a uno de los emigrantes ecuatorianos y decide mudarse a residir en otro lugar, porque "tras soportar por treinta años la invasión de los afroamericanos primero, después de hispanos y finalmente de hindúes e iraníes, habían decidido mudarse a otra zona" (2014, p. 10).

Sobre la emigración de ecuatorianos a Europa, en el cuento "Cara de bovino deprimido", de Adrián Carrasco Vintimilla, en un palmario ejemplo de inserción de una historia ficticia dentro de otra de mayores dimensiones, se patentiza la visión peyorativa que tiene una europea en contra de un emigrante ecuatoriano. En este relato, la doctora italiana Giuletta al referirse a los afanes investigativos de Manuel Sarango, quien desea saber qué identidad le atribuyen en Italia a Byron Moreno, un ex árbitro ecuatoriano de fútbol de "ojos somnolientos y tristones. De ahí vino lo de bovino deprimido" (2011, p. 40) manifiesta que está harta de esa chifladura de su pareja sentimental: "no tengo por qué hacerme cargo de esa manía de los sudamericanos. Creen conocer a todos los que se cruzan por la vía (...) nadie sabe de dónde vino, ni del país, ni de sus padres, peor de lo que él busca, el por qué la Plaza lleva su nombre, jnadie sabe nada!" (p.17). Tiempo después, cuando Giuletta y Manuel estaban resentidos, ella relata que buscaba maneras de reconciliarse, por lo que le ofrece un café y él le responde que acepta la invitación; sin embargo, incluso, la inmediata respuesta del indígena ecuatoriano ella la interpreta como una evidencia de su sumisa condición subalterna: "sí, contestó con esa humildad de su gente, incapaz de mirarte a la cara, para que sepas si en verdad lo desea, o si lo acepta solo por no contrariarte" (p.18).

Esta actitud de la italiana, de mirar a Manuel Sarango como un ser inferior, tiene otras variadas formas de expresarse, así en la ocasión en que visitaron el país de ella, mientras vagabundeaban por la ciudad de Messina, Giuletta no desaprovecha la oportunidad para descalificar a la tierra de origen del ecuatoriano. En su propia versión 
de lo acontecido manifiesta: "el Sur realmente me disgusta, comenté para que me oyera Manuel, así debe ser América, todos son descarados y harapientos" (20). Horas más tarde, cuando continuaban con la investigación sobre la identidad de Byron Moreno, sin mayor conocimiento de causa, se pronuncia en contra de los emigrantes sudamericanos, al repetir en sentido irónico, una de las versiones recibidas: "fue poeta, fue juez, pero nunca un sudaca apestoso" (p. 23).

Con las investigaciones realizadas por Manuel se desprende que luego de que el ex árbitro de fútbol Byron Moreno fue acusado de haberse vendido en favor de la selección de Corea y, de manera simultánea, perjudicar a Italia, en el Campeonato Mundial de Fútbol del año 2002, los italianos se vengaron en contra de todos los ecuatorianos, a quienes caricaturizaron y estereotiparon como personas que solo sirven para el trabajo físico; incluso los periódicos difundieron este tipo de estigmatización, así "en un diario salió un fotomontaje de una paisana arrodillada fregando el piso con el rostro de Moreno, con esa carota de aburrimiento. Como si no supiéramos hacer otra cosa" (p. 40). Las citas realizadas patentizan que el complejo proceso de animalización en contra de Byron Moreno, el cual se inicia con la denominación del cuento ("Cara de bovino deprimido") y la portada de la publicación que lo contiene; sin embargo, en el desarrollo de la historia esta animalización no solo se extrapola a Manuel Sarango, como protagonista del cuento analizado e investigador de la identidad que se le atribuye en Italia a otro ecuatoriano, sino que se hace extensivo al resto de emigrantes ecuatorianos en Italia, a quienes al homologarlo con el "tristemente célebre" ex árbitro de fútbol se los compara, de manera tácita, con el buey domesticado que constituye el "símbolo de sacrificio, sufrimiento, paciencia y trabajo" (Cirlot, 1992, p. 136) y, en ese sentido, se los cataloga como personas incapaces de realizar actividades intelectuales o que requieren algún nivel, aunque sea mínimo, de calificación profesional.

En este mismo cuento, en la ocasión en que Giuletta invita a su amiga alemana Beate para salir a un bar a servirse una copa de licor y se siente amenazada por la supuesta atracción mutua entre Manuel y Beate, la italiana, una vez más, se refiere en términos despectivos al emigrante ecuatoriano, al poner de manifiesto que "Manuel se portaba muy servil, con las dos claro, pero no dejaba de mostrar su perturbación a tal punto que llegué a arrepentirme de la tal invitación" (Carrasco, 2011, p. 47). Sin embargo, Giuletta, que había creído que, por necesidad, Manuel siempre estaría a su lado soportando todos sus maltratos xenófobos y racistas, pone de manifiesto su frustración, por cuanto 
gracias a un trabajo que encontró, el ecuatoriano puede tomar distancias: "logró liberarse de todas las amarguras y resentimientos conmigo -por lo menos así lo creíacuando obtuvo esa pega ${ }^{3}$ de corresponsal de un periódico de su país. El maldito logró zafarse" (p. 49).

En relación al trato discriminatorio que reciben las mujeres emigrantes ecuatorianas que trabajan en el servicio doméstico en España, por su condición de tales, hay dos cuentos que lo recrean de esta manera. En "El mejor trabajo", de Eliécer Cárdenas Espinoza, la protagonista Ubaldina comenta que cuando se presentó al domicilio en donde iba a laborar cuidando a un anciano, la patrona le explica que se iban a mudar unos parientes a ocupar el primer piso de la casa del anciano, porque "no iban a dejar que una sudaca morenucha se pasara allí sola con el viejo" (2004, p. 123).

Este trato diferenciado en contra de las emigrantes ecuatorianas en Madrid también se explicita en el relato "Doña Elvira", de Gladys Rodas Godoy, en donde se pone de manifiesto que "con el primer día llegaron las indicaciones, esas pequeñas y grandes diferencias que a veces le resultaban difíciles de aceptar. La vajilla separada, el poco descanso, ningún permiso fuera de las horas libres del sábado y domingo, la seguridad social después de seis meses de prueba" (2014, p. 71). En este mismo relato se advierte un caso de explotación laboral, por cuanto la emigrante ecuatoriana trabaja muchas horas extras, incluso fuera de la casa de la patrona, para un hijo de esta; sin embargo, al término del mes no le reconocen nada por el desempeño de esas actividades adicionales y cuando se decide a reclamarle y amenaza con denunciarla en la parroquia, por su vulnerable condición de indocumentada, la respuesta de doña Elvira es muy tajante y amenazadora: "Tú te vas a la parroquia y yo me voy a la policía a denunciar que me has robado, así que tú decides" (p. 73).

Los dos ejemplos citados ponen de manifiesto que algunas emigrantes ecuatorianas en la capital de España se sienten discriminadas y tratadas como seres inferiores y, aunque de ello tienen plena conciencia, lo racionalizan para sí mismas y no encuentran una explicación lógica; sin embargo, por la necesidad de generar los recursos económicos que les permitan sobrevivir ellas mismas y sus respectivas familias, que permanecen en

\footnotetext{
${ }^{3}$ Actividad que realiza, de manera habitual, una persona para ganarse la vida (Asociación de Academias de la Lengua Española, 2010).
} 
el Ecuador o ya han sido reunificadas, no les queda otra opción que aceptar lo que sea con tal de conservar el trabajo.

\section{Algunas manifestaciones de xenofobia y racismo en contra de los emigrantes}

\section{Expresiones de xenofobia de ciertos nativos de los países de destino}

La xenofobia se refiere al conjunto de "actitudes, prejuicios y comportamientos que rechazan, excluyen y frecuentemente difaman a una persona o colectivo de personas basándose en la percepción de que vienen de fuera o son extranjeros con respecto a la comunidad, sociedad o identidad nacional de referencia" (Comisión Europea, 2012, p. 212). Para analizar el problema de la xenofobia, en contra de los trabajadores migrantes provenientes del Sur del planeta, resulta pertinente recordar el planteamiento del sociólogo norteamericano Immanuel Wallerstein, quien manifestaba que "en todos los sistemas históricos anteriores, la xenofobia entrañaba una consecuencia fundamental en el comportamiento: la expulsión del 'bárbaro' del espacio físico de la comunidad, la sociedad, el grupo interno; la versión extrema de esta expulsión era la muerte" (1991, p. 55). Sin embargo, de lo expresado, en una época en la que se ha superado el racismo biológico, pero el cultural se encuentra en plena vigencia, el rechazo y la fobia en contra de los migrantes provenientes del Sur no viene dado porque sean de una "raza distinta", sino porque aparecen vinculados a dos factores: la diferencia cultural y la imagen de "peligrosidad" o "desorden" social (delincuencia, tráfico de drogas).

Las manifestaciones de xenofobia, en los Estados nacionales del Hemisferio Norte, se acrecientan con la masiva llegada de trabajadores migrantes procedentes del Sur, motivo por el cual, desde el año de 1992, ya Europa constituía un continente en donde los 13 millones de ciudadanos no comunitarios "estarían marginados en sus derechos sociales, y vivirían en guetos; se verían privados de la libertad de circulación, desprovistos de los derechos políticos y considerados, de forma permanente, como los responsables de todos los males (...). Se trataría de un mal plagiado de la democracia Griega de los emigrados, que serían los nuevos esclavos" (Sánchez, 1994, p. 31).

Los ecuatorianos en España, como dice Andrea Mora Umaña, sí son víctimas de ataques xenofóbicos de parte de ciertos nativos, razón por la cual "se han reportado muchos incidentes en que se ha tratado de forma violenta a ecuatorianos, muchas veces 
no es posible determinar si se tratan de ataques xenófobos, pero que por cuestiones obvias no se puede negar que lo son, como el reportado en octubre del 2007, cuando se atacó a una joven ecuatoriana en un metro de la ciudad de Barcelona y su agresor evidenciaba que se trataba de un hecho racista" (2010, p. 388). Es más, los resultados de la investigación realizada por Gloria Camacho Zambrano ratifican la percepción de la xenofobia en contra de los ecuatorianos:

El 23\% de ecuatorianas declararon haber vivido situaciones en que ellas se sintieron atropelladas o despreciadas por su origen o por su condición de inmigrantes. Son numerosos los relatos sobre este tipo de vivencias, algunos de los cuales no dejan de sorprender, en tanto dan cuenta del nivel de rechazo y xenofobia que reinan en algunos ambientes de la sociedad española e, inclusive, entre las propias personas que se están beneficiando del trabajo de las inmigrantes (2010, p. 201).

Una forma indirecta de expresión de xenofobia en España se pone de manifiesto en momentos de crisis en los que se echa la culpa de todos los males a los inmigrantes económicos provenientes del Sur, actitud que se hace pública cuando los nativos de España afirman que "todas las becas se las dan a los inmigrantes", "los inmigrantes nos quitan el trabajo", "los servicios públicos están saturados por culpa de los inmigrantes", "la inmigración ha aumentado la inseguridad ciudadana" (Mora, 2010, p.192). Sin embargo, la realidad es muy distinta como lo demuestran varios estudios, según los cuales "los extranjeros son contribuyentes netos (ingresan al Estado más de lo que gastan) en casi todo el continente (...). Aun así, varios informes presentados en España colocan a los inmigrantes como contribuyentes netos en sanidad. El motivo es que enferman menos, suelen ser más jóvenes y con mayor necesidad de trabajo que los autóctonos" (p. 193).

La expresión de xenofobia, por parte de algunos nativos de los Estados nacionales de destino, en contra de los emigrantes ecuatorianos se representa y recrea en varios cuentos estudiados. Así, en Estados Unidos, la xenofobia está muy presente; por ello, una vez que se acabó el peligro del socialismo real capitaneado por la ex URSS y los países satélites de este sistema sociopolítico, los migrantes provenientes del Sur se convierten en los nuevos enemigos del imperialismo norteamericano, tal como lo expresa el narrador de uno de los relatos testimoniales de Galo Galarza Dávila, en el 
cual un protagonista, al formular y responder una pregunta retórica en la interacción comunicativa que establece, se expresa de la siguiente manera: “¿Usted sabe quiénes somos sus enemigos, una vez que se acabaron los comunistas? Pues nosotros, jovencito, nosotros los inmigrantes ilegales, los desarrapados indios de Deleg, de Uyumbicho, de Vinchoa. A nosotros se nos debe perseguir, atormentar, eliminar (...). Nos consideran tan peligrosos como narcotraficantes o como terroristas que les ponen bombas" $(2009, \text { p. } 75)^{4}$.

Sobre los emigrantes en dirección a España, en el cuento "Cara de bovino deprimido", de Adrián Carrasco Vintimilla, se hace referencia al ya mencionado ataque xenofóbico del que fue víctima la adolescente ecuatoriana en el metro de la ciudad de Barcelona, detestable hecho que hace emerger un sentimiento de general rechazo en contra de este tipo de comportamientos que, lamentablemente, son muy comunes en diferentes partes del mundo; pues, como lo expresa uno de los narradores de la ficción en referencia: "Te diré que tardé algún tiempo en darme cuenta de que lo que ocurrió no fue tan grave, solo cuando en el mismo metro de Barcelona uno de esos tarados agredió a una chica paisana nuestra. Sí, fue hace poquito, claro que lo vi en la tele ¡Carajo!, eso sí era para templarse de la rabia (...), pero para maltratar a la gente, en todas partes" (2011, p. 26).

En este mismo cuento, en la ocasión en que Aarón Bello lleva a Manuel Sarango a uno de los bares de Barcelona, el solo hecho de que este, por simple curiosidad, se detenga a observar y escuchar la conversación que mantienen dos catalanes constituye razón más que suficiente para que uno de los contertulios reaccione de manera virulenta en contra del aborigen ecuatoriano: “’Vas a tener que joderte. Eres un chorizo vulgar. Así que tira palante sudaca fills de puta antes de que te parta la cara de un porrazo' (...). 'Fuera de mi plaza moro comemierda, te voy a matar puto inmigrante'. Agarró un banco y picó como una bestia contra Sarango, pero no alcanzó a tocarlo porque el hombre había ya comenzado a correr hasta situarse a distancia de una legua" (p. 27).

\footnotetext{
${ }^{4}$ De similar manera, en el cuento "La puta madre patria", de Miguel Antonio Chávez, Naief, uno de los personajes protagónicos, hace referencia a la xenofobia que prevalece en la ciudad de Nueva York, sobre todo a partir de los atentados terroristas del 11 de septiembre de 2001: "vivió un tiempo en Nueva York y, paradójicamente, sintió que a raíz de los atentados del 11-S la ciudad más cosmopolita del mundo era también la más xenófoba hacia todo aquello que tuviera vestigios del mundo árabe, y él tenía, pues, esa ascendencia inequívoca heredada de sus padres" (2012, p.102).
} 
En el cuento "Redoble de campanas en Madrid", de Raúl Vallejo Corral, la actitud xenófoba de algunos españoles es puesta de manifiesto a través de la narración de varios casos que se ubican entre la ficción literaria y la realidad real del comportamiento de los nativos de España en relación a la población extranjera. Así, cuando el médico de la policía española llega a tomar las muestras para verificar si el emigrante ecuatoriano Jaime es portador de SIDA, le espeta que "a todos estos sudacas les deberíamos dar una patada en el culo y mandarlos de regreso a su selva", actitud xenófoba que le hace recordar al protagonista del relato otras dolorosas experiencias de los ecuatorianos en España:

Ves las patadas que Sergi Xavier Martín Martínez, catalán de 21 años, le propinaba a una ecuatoriana de 16 años, en un tren de Ferrocalils de la Generalitat, el 7 de octubre de 2007, mientras le gritaba con furia “iinmigrante!”. Ves a María José, una adolescente ecuatoriana de 13 años, llevada con engaños hasta un descampado en las afueras de Colmenarejo, el 23 de julio de 2008; ahí, mientras Belén, adolescente española, le propinaba golpes por todo el cuerpo, incluida la cara, a una María José que estaba tumbada en el suelo, sus cinco amigas gritaban entre risas, como si se tratara de un videojuego: ¡Mátala, mátala! (Vallejo, 2013, p. 154).

\section{Algunas manifestaciones de racismo en contra de los ecuatorianos}

En directa relación con la xenofobia se encuentra el racismo, el cual se refiere a la supuesta superioridad biológica y/o cultural de una raza sobre otra. El racismo se manifiesta como rechazo a la diferencia o miedo a la otra cultura, sobre todo a los migrantes provenientes de los países pobres del Sur del planeta. Las soluciones para el racismo se pueden dar de dos formas: excluyendo al extraño, a través de detenciones ilegales, deportaciones, torturas o tratos crueles, la persecución, las ejecuciones extrajudiciales y hasta el genocidio; o, dominando o incorporando a la propia cultura del país de recepción. En este caso se expresa a través de la violación del derecho al trabajo, a la educación, a la salud, a la seguridad social, a la diversidad cultural, a la reunificación familiar y el acceso a la justicia (Salazar, 2016, p. 203). Y en casos extremos el racismo se puede convertir en la desmesura amenazante de la otredad; puesto que "el racista no pretende asimilar, ni convertir, ni tan siquiera someter a ese 
otro que, por serlo, es distinto y diferente y peligroso y enemigo en fin de su existencia más esencial, su impulso lleva, en última instancia, a la extinción, a la muerte de ese ser amenazador que se dibuja sobre el entorno de lo familiar" (Caparrós, 2010, p.26).

Una vez superadas las bases biologistas sobre las cuales se erigió el racismo clásico, en palabras del sociólogo francés Etienne Balibar, emerge el nuevo racismo, el racismo culturalista, el cual sigue en plena vigencia, aunque sus formas de expresión sean muy sutiles:

El nuevo racismo es un racismo de la época de la 'descolonización', de la inversión de los movimientos de población entre las antiguas colonias y las antiguas metrópolis, y de la escisión de la humanidad en el interior de un único espacio político (...); un racismo cuyo tema dominante no es la herencia biológica, sino la irreductibilidad de las diferencias culturales; un racismo que, a primera vista, no postula la superioridad de determinados grupos o pueblos respecto a otros, sino 'simplemente' la nocividad de la desaparición de las fronteras, la incompatibilidad de las formas de vida y de las tradiciones: lo que se ha podido llamar con razón un racismo diferencialista(Balibar, 1991,p.37).

En los distintos países del Norte una evidencia irrecusable del neorracismo culturalista constituyen las remuneraciones mucho más bajas que reciben los trabajadores migrantes, por el desempeño de los mismos trabajos que hacen los nativos: "El monto de los salarios de los inmigrantes es bajo en términos absolutos y relativos. En comparación con los que obtienen los trabajadores nativos que ocupan sus mismos puestos de trabajo, las estimaciones más tímidas plantean que los inmigrantes ganan entre el $10 \%$ y el $30 \%$ menos (...). Las estimaciones más elevadas sitúan esta diferencia entre el $30 \%$ y $50 \%$ " (Thayer, 2009, p. 228).

En relación a las expresiones de racismo en contra de los trabajadores migrantes, los ecuatorianos que han emigrado hacia Estados Unidos denuncian que son víctimas propiciatorias de estas detestables actitudes, tal como lo patentiza el emigrante César Rivadeneira, quien luego de permanecer de manera ilegal durante más de veinte y tres años decide retornar al Ecuador, nueva circunstancia en la que cobra plena conciencia del racismo que lo afectó y de su doble segregación, por gay y migrante proveniente del Sur: "Eso fue la confirmación para mí de que, sí, hay discriminación, hay abuso, hay 
injusticia, hay hasta cierto punto odio con respecto a los latinos y a los gays, y yo siendo ambos" (Hill y Rivadeneira: 2014, p. 110).

En el testimonio brindado por Óscar Paredes Morales se patentiza que la percepción idílica que tenía de Estados Unidos, como un país en el que todos vivían, en el marco del respeto a los derechos humanos fundamentales se fue al piso en cuanto llegó al aeropuerto: "Encontré un país hostil, egoísta, muy racista, que no respetaba los derechos de los demás. Los desamparados permanecían parados en las calles temblando por el frío y hambrientos" (2014, p. 138).

En relación al racismo existente en España es pertinente destacar que frente a los brotes de racismo emerge el otro lado de la medalla, por lo que es necesario relievar y "hacer justicia a la mayor parte del pueblo español que rechaza esta situación y se solidariza cada vez más con los nuevos proscritos de la tierra. Sindicatos, ONG, movimientos asociativos, Iglesia, hombres y mujeres de buena fe, jóvenes (...) protestan y actúan para rechazar el trato indigno que reciben estos trabajadores" (Goytisolo, 2000, 125). Por supuesto que esta actitud positiva de gran parte de la población ibérica pone de manifiesto que España no es más racista que el resto de las sociedades europeas; sin embargo, sí lo es tanto como ellas, con su propio tono, sus fobias tradicionales, sus miedos y fantasmas. Entre las causas de este racismo se pueden mencionar: "miedo al paro y angustia ante un porvenir incierto; aumento de la competencia en el mercado de trabajo; el color, el sexo, la edad, la cultura, el nombre, la religión; todo se convierte en un factor de discriminación en el despiadado liberalismo del mercado" (p. 151).

El racismo en contra de los emigrantes ecuatorianos es, asimismo, un tema recurrente en algunos de los cuentos ecuatorianos analizados. En el relato "Vendaval", de Zoila María Castro, que alude a la emigración desde el Ecuador hacia Estados Unidos, se pone de manifiesto que una amiga y compatriota de la narradora protagonista es muy consciente del racismo de la sociedad estadounidense y que afecta, en primer término a los negros, por el solo hecho de tener ese color de piel. En palabras de esta emigrante: "El problema del negro, señora Medrano, es el color, puramente el color. Es el origen de su estigma social, que no lo es de haber sido sus padres esclavos. Ves un negro y lo asocias instantáneamente a vandalismo. Súbitamente brota el temor de ser atacada, de padecer alguna forma de atropello" (1981, p. 215). 
Sobre la emigración a España, hay dos cuentos que son muy elocuentes en torno a la presencia de algunas expresiones de racismo de ciertos nativos en contra de los emigrantes ecuatorianos. El narrador protagonista del cuento "Ya no tengo que llorar", de Carlos Carrión Figueroa, cuando se encuentra junto a su amada esposa Maribel se siente tan feliz que ni siquiera le importan las manifestaciones de racismo con las que tiene que lidiar en las calles de la capital española; por ello, mientras pasea cogido de la mano no le importaban "los ojos rencorosos de los racistas, los insultos de indio, sudaca, gilipollas, nada" (2005, p. 18). Y en el momento en que se embriaga y va camino a quitar la vida a Maribel, por haberlo traicionado con otro hombre, ni por el estado emocional por el que atraviesa deja de pensar en lo que comentarán los españoles xenófobos y racistas respecto de su comportamiento criminal azuzado por el licor que ha consumido, quienes dirán: "Eso son los inmigrantes ecuatorianos, unos ebrios de los cojones. Lo que no dirán es que también hay arrechos capaces de matar a la mujer que aman, para librarse de la desgracia o hundirse más en ella y dejar de llorar" (p. 24).

En el cuento "Historias de inmigrantes", de Mario Campaña Avilés, la presencia de los grupos racistas y xenófobos que tratan de limpiar la ciudad de Barcelona de la presencia de "inmigrantes y mendigos" es muy directa, conforme se pone de manifiesto cuando la pareja de ancianos protagonistas del cuento evacuan el piso del que iban a ser desalojados por incapacidad de pago del canon de arrendamiento. En altas horas de la noche, aunque los ancianos saben que la puerta de acceso al metro ya se encuentra cerrada y ellos no tienen rumbo cierto que tomar o destino preciso a dónde llegar, igual emprenden el camino sin ni siquiera importarles la amenaza de convertirse en víctimas de los racistas, que deambulan por las calles de la ciudad condal; porque enseguida que inician el recorrido "vieron un grupo de cinco muchachos vestidos de negro y de cabezas rapadas, de esos que salen a la calle en la noche con manoplas y cadenas a cazar inmigrantes y mendigos" (2012, pp. 224-225).

\section{CONCLUSIONES}

Una de las más desagradables problemáticas que experimentan algunos emigrantes ecuatorianos, cuando arriban a los países de destino y mientras permanecen en ellos, es el de ser tratados como los "otros", los extranjeros, los forasteros, los desechables, los descartables, los sustituibles y, a consecuencia de ello sentirse afectados por la exclusión, la discriminación, la explotación, la 
dominación y el menosprecio. Una evidencia de lo afirmado constituye la limitación para ingresar a los países del Hemisferio Norte, a través de la admisión selectiva, la legalización de la expulsión o la prohibición del acceso, mediante la construcción de muros, vallas y alambradas. Por supuesto que esta construcción del sujeto emigrante como el "otro" se lo hace desde el punto e intereses de vista de quienes detentan el poder, conforme es fácil de advertirlo en los cuentos de Zoila María Castro, Adrián Carrasco Vintimilla, Eliécer Cárdenas Espinoza, Galo Galarza Dávila, Gilda Holst y Gladys Rodas Godoy, en cuyos textos se patentiza que los ecuatorianos son muy conscientes del estereotipada condición de ser los "otros"; sin embargo, por la necesidad de trabajar para poder satisfacer las necesidades básicas no les queda más opción que aceptar la subalternidad frente a los nacionales de los países de llegada, quienes si son sujetos de plenos derechos y garantías.

En estrecha relación con la otredad de los migrantes advienen algunas manifestaciones de xenofobia, que se refieren a las actitudes, prejuicios y comportamientos que rechazan, excluyen y difaman a los extranjeros, tal como lo testimonian algunos emigrantes ecuatorianos consultados y se representa en los cuentos de Adrián Carrasco Vintimilla, Galo Galarza Dávila, Raúl Vallejo Corral y Miguel Antonio Chávez, en los cuales se evidencia que algunos ecuatorianos, de manera injusta, son vinculados con el terrorismo, el narcotráfico, la delincuencia, el alcoholismo u otros problemas sociales, por lo que se convierten en víctimas de la xenofobia, de parte de ciertos patrones, compañeros de estudios, usuarios de servicios públicos e incluso de ciertos miembros de instituciones públicas, como la policía, todos quienes olvidándose que la mayoría de sus antepasados algún día también fueron migrantes, no dejan de exteriorizar su sentimiento xenofóbico en contra de los ecuatorianos, los cuales por limitaciones económicas no pueden regresar al añorado país de origen y a la cercanía de los familiares, amigos y más seres queridos que se quedaron en él. 
El racismo, que alude a la supuesta superioridad biológica o cultural de una población en desmedro de otra, obstruye el ejercicio de los derechos de los migrantes, por ser originarios de un país pobre, pertenecer a un grupo humano distinto, poseer un color de piel diferente, tener otros rasgos culturales o no tener los documentos exigidos para ingresar o permanecer en los países de de destino, conforme lo demuestran los resultados de investigaciones sobre la migración internacional y la recreación literaria en los cuentos de de Zoila María Castro, Carlos Carrión Figueroa y Mario Campaña Avilés, en donde se patentiza el prejuicio racial en contra de los ecuatorianos, que solo aspiran mejorar los ingresos y nivel de vida de sí mismos y de sus respectivas familias, aunque para conseguir este preciado objetivo tengan que ejecutar los trabajos más duros, riesgosos, precarios y menos remunerados y, simultáneamente, deban soportar, con estoico mutismo, los golpes del racismo y lo puedan hacer gracias al apoyo material y moral del entorno familiar y de amistades más cercanos, así como de ciudadanos de corazón generoso, espíritu solidario y mente abierta, que también están dispuestos a reconocer el trabajo y aporte de los ecuatorianos y coadyuvar en la lucha por exigir el cumplimiento de los derechos y garantías, por su sola condición de seres humanos.

\section{REFERENCIAS BIBLIOGRÁFICAS}

Asociación de Academias de la Lengua Española (2010). Diccionario de americanismos. Madrid: Santillana.

Barrera, L. (1997). Apuntes para una teoría del cuento. En C. Pacheco, y L. Barrera Linares (Comps.), Del cuento y sus alrededores: Aproximación a una teoría del cuento (pp. 29-42).Caracas: Monte Ávila.

Camacho, G. (2010). Mujeres migrantes: trayectoria laboral y perspectivas de desarrollo humano. Buenos Aires: Consejo Latinoamericano de Ciencias Sociales.

Campaña, M. (2012). "Historias de inmigrantes". En Antes bajaban en tren (pp. 221 225). París: Meet.

Caparrós, N. (2010). "Del narcicismo de las pequeñas diferencias al racismo". En I. Sanfeliu y J. Varona (eds.), Migración, racismo y poder: el narcicismo de las pequeñas diferencias (pp. 12-28). Madrid: Biblioteca Nueva. 
Cárdenas, E. (2004). “El mejor trabajo”. En Relatos del día libre: cuentos (pp. 117-132). Quito: Eskeletra.

. (2014). "La Niña Pupusa”. En El jabalí en el bar: historias de viajeros y emigrantes (pp. 9-22). Cuenca: Imprenta Mercedes.

Carrasco, A. (2011). Cara de bovino deprimido. Prólogo de Felipe Aguilar. Cuenca: Universidad de Cuenca.

Carrión, C. (2005). "Ya no tengo que llorar", en VIII Bienal del cuento ecuatoriano Pablo Palacio (pp. 15-34). Quito: CEDIC.

Castro, Z. M. (1981). En el norte está El Dorado. Guayaquil: Casa de la Cultura Ecuatoriana “Benjamín Carrión”, Núcleo Provincial del Guayas.

Chambers, I. (1995). Migración, cultura e identidad. Buenos Aires: Amorrortu.

Chávez, M. A. (2012). "La puta madre patria”. En Tiros de gracia: neoficción ecuatoriana (pp. 97-116). Selección y prólogo de Renata Egüez. Quito: Casa de la Cultura Ecuatoriana "Benjamín Carrión".

Cirlot, J. E. (1992). Diccionario de símbolos. 2 ed. Barcelona: Labor.

Comisión Europea (2012). Glosario sobre migración y asilo. 2.0, Un instrumento para una mayor comparabilidad. 2 ed. Bruselas: Red Europea de Migraciones.

Estébanez, D. (1999). Diccionario de términos literarios. Madrid: Alianza.

Galarza, G. (2009). La Dama es una trampa. 2 ed. Quito: Eskeletra.

Goytisolo, J. y Naïr, S. (2000). El peaje de la vida: Integración o rechazo de la emigración en España. Madrid: Aguilar.

Hill, M. D. y Rivadeneira, C. E. (2014). "Presos de la libertad: el testimonio de una pareja binacional gay". En D. Falconí Trávez (ed.). "Me fui a volver”: narrativa, autorías y lecturas teorizadas de las migraciones ecuatorianas (pp. 95-115). Quito: Corporación Editora Nacional.

Holst, G. (2006). "47 Coldwater Drive o la pregunta”. En Bumerán (pp. 59-61). Báez.editor.es.

Mora, A. (2010). "Inmigración, participación e integración ciudadana: hacia una nueva configuración de la ciudadanía”. En Á. Solanes Corella (ed.). Derechos humanos, migraciones y diversidad (pp. 175-207). Valencia: Tirant lo Blanch. . (2011). Entrevista concedida para la Revista Electrónica Spondylus, de la Universidad Andina Simón Bolívar, Sede Ecuador, respecto de la migración de ecuatorianos a España. [Consultado el 25 de noviembre de 2013]. 
Mora, A. M. (2010). "El estudio de la inmigración desde la teoría de dinámica de tropas: el caso particular de los inmigrantes ecuatorianos en España". En Ciencias Económicas 28, 2, (pp. 369-390).

Murillo, J. (2009). Rostros de la migración. Experiencias comentadas de inmigrantes colombianos y ecuatorianos en España. Bogotá: Códice.

Núñez, J. (2014). “Los muros de la infamia”. En página editorial de Diario El telégrafo de Guayaquil.

Paredes, Ó. (2014). "Yo: hijo del sol, águila de vuelo libre, guerrillero de la paz". En D. Falconí Trávez (ed.). "Me fui a volver": narrativa, autorías y lecturas teorizadas de las migraciones ecuatorianas (pp. 125-139). Quito: Corporación Editora Nacional.

Ramírez, F. y Ramírez, J. P. (2005). La estampida migratoria ecuatoriana. Crisis, redes transnacionales y repertorios de acción migratoria. 2 ed. Quito: Centro de Investigaciones CIUDAD.

Rodas, G. A. (2014). La casa ajena (relatos). Quito: s.n.t.

Salazar, Y. (2014). La emigración internacional en la novelística ecuatoriana. Tesis de Doctorado no publicada, Universidad del País Vasco, San Sebastián. . (2016). El sujeto emigrante en el cuento ecuatoriano 1972-2014.Tesis de Doctorado no publicada, Universidad Complutense de Madrid.

Sánchez González, J. et al. (1994). El otro muro: migración, racismo, xenofobia. Madrid: Editorial Complutense.

Serrano Sánchez, R. (2013). "Sujeto migrante en el cuento ecuatoriano del siglo XX y el entre siglo". En Memorias deI XI Encuentro Sobre Literatura Ecuatoriana "Alfonso Carrasco Vintimilla" (Tomo I, pp. 193-222). Cuenca: Universidad Estatal de Cuenca.

Thayer, L. E. (2007). Inmigrantes ecuatorianos en la comunidad de Madrid: la apropiación del espacio y la expropiación del tiempo. Madrid: Editorial Complutense.

Vallejo, R. (2013). "Redoble de campanas en Madrid". En Pubis equinoccial (pp. 149155). Bogotá: Mondadori.

Wallerstein, I. y Balibar, E. (1991). Raza, nación y clase. Las identidades ambiguas. Madrid: IEPALA. 